\title{
Pleomorphic Adenoma of
}

\section{the Parotid: Extracapsular Dissection Compared with Superficial Parotidectomy-A 10-Year Retrospective Cohort Study}

\author{
Maria Giulia Cristofaro, ${ }^{1}$ Eugenia Allegra, ${ }^{2}$ Amerigo Giudice, ${ }^{3}$ Walter Colangeli, ${ }^{1}$ \\ Davide Caruso, ${ }^{1}$ Ida Barca, ${ }^{1}$ and Mario Giudice ${ }^{1}$ \\ ${ }^{1}$ Department of Oral and Maxillofacial Surgery, UMG of Catanzaro, Viale Europa, 88100 Catanzaro, Italy \\ ${ }^{2}$ Department of Otolaryngology, UMG of Catanzaro, Viale Europa, 88100 Catanzaro, Italy \\ ${ }^{3}$ Department of Odontostomatology, UMG of Catanzaro, Viale Europa, 88100 Catanzaro, Italy \\ Correspondence should be addressed to Eugenia Allegra; eualle@unicz.it
}

Received 11 May 2014; Accepted 25 August 2014; Published 21 October 2014

Academic Editor: Mustafa Gurhan Ulusoy

Copyright ( 2014 Maria Giulia Cristofaro et al. This is an open access article distributed under the Creative Commons Attribution License, which permits unrestricted use, distribution, and reproduction in any medium, provided the original work is properly cited.

\begin{abstract}
The purpose of this study was to investigate the complication rates and effectiveness of extracapsular dissection compared with superficial parotidectomy for pleomorphic adenomas of the parotid gland from 2002 to 2012. The authors carried out a retrospective cohort study of 198 patients with pleomorphic adenomas of the parotid gland. Extracapsular dissection (ED) or superficial parotidectomy (SP) was performed. The recurrence rate and complications of the two surgical techniques were measured with a univariate analysis of each variable using the appropriate statistical analysis (chi-squared test or $t$-test). A total of 198 patients were enrolled between January 2003 and December 2012. The study included 97 females (48.99\%) and 101 males (51.01\%) whose mean age was 50.97 years (range 14-75). The type of surgery performed was ED in 153 patients $(77.27 \%, 80$ males and 73 females) and SP in 45 patients $(22.73 \%, 21$ males and 24 females). The mean follow-up time was $61.02+/-4.9$ months for the patients treated with ED and $66.4+/-4.5$ months for the patients treated with SP. Transient facial nerve injury and facial paralysis were significantly more frequent after SP than after ED $(P=0.001$ and $P=0.065$, resp.). No significant differences in capsular rupture, recurrence, and salivary fistula were observed after SP or ED: $2.2 \%$ versus 3.9\%, $2.2 \%$ versus $3.3 \%$, and $2.2 \%$ versus $0.65 \%$, respectively. Extracapsular dissection may be considered the treatment of choice for pleomorphic adenomas located in the superficial portion of the parotid gland because this technique showed similar effectiveness and fewer side effects than superficial parotidectomy.
\end{abstract}

\section{Introduction}

Pleomorphic adenomas are the most common benign tumors of the salivary gland, comprising $85 \%$ of all salivary gland neoplasms and $60 \%$ of the benign tumors of the parotid gland [1-4].

The surgical management of a pleomorphic adenoma has been the subject of controversy for many years, mainly because of the risks of facial nerve injury, capsular rupture, and recurrence [5-8]. A superficial or total parotidectomy involves the resection of a considerable amount of normal parotid tissue with dissection of the facial nerve, causing facial nerve injury and the loss of parotid function [9]. These risks prompted surgeons to adopt less invasive surgical techniques such as extracapsular dissection (ED), which involves the removal of only the tumor and an area of normal parotid parenchyma and the preservation of parotid function, thus minimizing the incidence of facial nerve injury and Frey's syndrome [10-12].

The purpose of this study was to investigate the complication rates and effectiveness of ED and SP for the treatment of pleomorphic adenomas of the parotid gland from 2002 to 2012. 


\section{Materials and Methods}

Patients with a pleomorphic adenoma of the parotid gland treated between January 2003 and June 2012 were included in this retrospective cohort study. The diagnosis of a pleomorphic adenoma was established by ultrasonography, head and neck CT or MRI, and FNAC (fine needle aspiration cytology) or FNAB. To be included in the study sample, the patients had a tumor located in the superficial portion of the parotid gland. The mean lesion size was $3.0+/-0.5 \mathrm{~cm}$ on echography or magnetic or computed tomography. The choice of the surgical technique was randomly assigned.

The study was approved by the appropriate ethics committees, and informed consent was given by the patients.

2.1. Superficial Parotidectomy. The skin incision was performed while considering the natural folds of the face and neck flexion (Redon incision), and the incision starts (vertical segment anterior) from the preauricular region and extends up to the ear lobe insertion, reaches the anterior margin of the mastoid, and then continues posteriorly along the mandibular angle.

The superficial muscular aponeurotic system (SMAS) was elevated, and the greater auricular nerve was identified and preserved. The common trunk of the facial nerve was identified, isolated, and controlled by continuous facial nerve monitoring with a neurostimulator (800 Neurosign nerve monitor equipment). After removal of the tumor, hemostasis was ensured using bipolar coagulation, and the facial planes and skin were closed.

2.2. Extracapsular Dissection. The skin incision was the same as in the SP. Careful attention was paid to maintaining the integrity of the tumor capsule by performing a wide excision of the parenchyma surrounding the wound (approximately 2$3 \mathrm{~mm}$ from the tumor) but without identification of the facial nerve.

In patients with a mass on the angle of the jaw (parotid tail), a modified technique was used. The skin incision of the preauricular region was avoided, and the marginal mandibular branch of the facial nerve was identified and preserved.

2.3. Statistical Analysis. The significant difference of the recurrent rates and complications of the two techniques was determined using a univariate analysis of each variable with the appropriate test (chi-squared test or $t$-test). The level of statistical significance was set at $P=0.05$.

\section{Results}

A total of 198 patients with pleomorphic adenomas of the parotid were included in this study; 97 were females (48.99\%) and 101 males (51.01\%) with a mean age of 50.97 years (range 14-75). The demographic characteristics of the study population are described in Table 1.

An ED was performed in 153 patients (77.27\%, 80 males and 73 females), and an SP was performed in 45 patients
TABLE 1: Demographic characteristics of the study population.

\begin{tabular}{lccc}
\hline & ED $=153$ & $\mathrm{SP}=45$ & $P$ value \\
\hline Sex & & & $\mathbf{0 . 6 1 1}^{*}$ \\
$\quad$ Male & 80 & 21 & \\
$\quad$ Female & 73 & 24 & \\
Mean age & $58 \pm 1.6$ & $51 \pm 2.8$ & $\mathbf{0 . 0 6 3}$ \\
Mean lesion size & $3.0 \pm 0.5$ & $2.5 \pm 0.8$ & $\mathbf{0 . 4 5 1}$ \\
Followup & $61.02 \pm 4.9$ & $66.4 \pm 4.5$ & $\mathbf{0 . 5 7 5}$ \\
\hline
\end{tabular}

$P$ value according $t$-test and ${ }^{*}$ Fisher's exact test (statistical significance with $P<0.05)$.

(22.73\%, 21 males and 24 females). The mean lesion size was $3.0 \pm 0.5 \mathrm{~cm}$ for ED and $2.5 \pm 0.8$ for SP treated patients.

The mean follow-up time was $61.02 \pm 4.9$ months for the patients treated with an ED and $66.4 \pm 4.5$ months for the patients treated with an SP.

In all patients, the postoperative course was normal without locoregional complications (edema and/or surgical site bleeding) or systemic complications (fever, etc.), and all the patients were discharged after an average of three days from surgery.

Histological examination of the surgical specimen agreed with the FNAB in all patients, confirming the diagnosis of pleomorphic adenoma.

The clinical examination took place on a monthly basis for the first three months, every three months for the first year and every 12 months for another four years for a total followup period of five years.

The imaging examinations occurred on a programmed schedule, with ultrasonography every three months for the first year, every six months for the second and third years, and every year for the fourth and fifth years. A CT scan or MRI was scheduled at the first, third, and fifth years. After five years, we determined that there was sufficient evaluation with ultrasonography every 24 months.

The postoperative complications are summarized in Table 2 .

In our study, we found that the SP has a higher rate of complications than the ED. A univariate analysis showed a statistically significant association between SP and the occurrence of at least one of the complications examined $(P=0.048)$.

Transient facial nerve injury and facial paralysis were significantly more frequent after SP than after ED (20\% versus $4.5 \%, P=0.001$, and $2.2 \%$ versus $0 \%, P=0.065$, resp.). The main injuries occurred in the mandibular branch with both techniques.

No significant differences in capsular rupture, recurrence or salivary fistula were observed after SP or ED: $2.2 \%$ versus $3.9 \%(P=0.587), 2.2 \%$ versus $3.3 \%,(P=0.714)$, and $2.2 \%$ versus $0.65 \%(P=0.355)$, respectively.

The patients with salivary fistulas were treated by aspiration, a pressure dressing, and a reduced intake of fluid. We had no cases of Frey's syndrome. There were no differences in esthetic satisfaction. 
TABLE 2: Differences of the recurrent rates and complications of ED versus SP.

\begin{tabular}{lccr}
\hline Postoperative complications & ED (total =153) & SP (total = 45) & $n^{\circ}(\%)$ \\
& $n^{\circ}(\%)$ & $9(20 \%)$ & \\
\hline Transient facial nerve injury & $7(4.5 \%)$ & $1(2.2 \%)$ & $\mathbf{0 . 0 0 1}$ \\
Facial paralysis & $0(0 \%)$ & $1(2.2 \%)$ & $\mathbf{0 . 0 6 5}$ \\
Capsular rupture & $6(6.9 \%)$ & $1(2.2 \%)$ & $\mathbf{0 . 5 8 7}$ \\
Recurrence & $5(3.3 \%)$ & $1(2.2 \%)$ & $\mathbf{0 . 7 1 4}$ \\
Salivary fistula & $1(0.65 \%)$ & $\mathbf{0 . 3 5 5}$ \\
\hline
\end{tabular}

$P$ value according chi-squared test (statistical significance with $P<0.05$ ).

\section{Discussion and Conclusions}

The two main aspects of parotid surgery for benign tumors are the removal of the lesion with adequate margins of healthy parotid tissue surrounding it and preservation of the facial nerve.

Superficial or total parotidectomy has been indicated for pleomorphic adenomas because of the high recurrence rates after enucleation of this benign tumor, which is often related to the incomplete excision or capsule rupture with the dissemination of tumor cells $[11,13]$.

A superficial or total parotidectomy involves the removal a considerable amount of normal tissue, and fewer branches of the facial nerve are dissected. Other complications are observed more frequently after SP than after ED, including Frey's syndrome, salivary fistula, and injury to the great auricular nerve. The literature data show that ED has similar effectiveness and fewer side effects relative to SP; ED minimizes the incidence of facial nerve paralysis and recurrence and has improved cosmetic results [14-17].

The statistical data collected in this study are in agreement with those reported in the literature and confirm the low morbidity associated with ED. Our incidence of transient facial nerve injury was significantly more frequent after SP than after ED.

The incidence declines from $26 \%$ after SP to $11 \%$ after ED $[1,12]$. This complication does not necessarily result from a branch of nervous neurotmesis. It sometimes results from surgical manipulation that causes a transient nerve injury, and it is proportional to the length of time the nerve is exposed during the surgery. In ED, the facial nerve is not exposed if it is not in contact with the tumor, and when the nerve is in contact with the tumor, only a small portion of the branches of the nerve are handled. The permanent facial nerve damage rate was lower in our data $(2.2 \%$ after SP versus $0 \%$ after $\mathrm{ED}, P=0.065)$ than reported in the literature $(4 \%$ after SP versus 3.5\% after ED) (1). In our experience, in a longterm of followup $(61.02 \pm 4.9$ months for the patients treated with ED and $66.4 \pm 4.5$ months for the patients treated with $\mathrm{SP})$, no significant differences in capsular rupture, recurrence, or salivary fistula were observed after SP or ED: $2.2 \%$ versus $3.9 \%(P=0.587), 2.2 \%$ versus $3.3 \%(P=0.714)$, and $2.2 \%$ versus $0.65 \%(P=0.355)$, respectively.

Frey's syndrome, which was not reported in our cases, is more frequent after SP than after ED, and its incidence ranges from $17 \%$ after SP to $3 \%$ after $\operatorname{ED}[7,8,10,18]$. ED is a microsurgery; in the hands of a novice surgeon or occasional parotid surgeon, it can become a high-risk surgery with various complications [17]. The clinical and statistical data showed a statistically significant association between SP and the occurrence of at least one of the complications examined $(P=0.048)$. For this reason, ED may be considered the treatment of choice for pleomorphic adenomas located in the superficial portion of the parotid gland. We recommend SP for tumors larger than $3.5 \mathrm{~cm}$ in diameter, when the lesion is located in the deep portion of the parotid gland or in cases of tumor recurrence. In fact, as Maruyama et al. [19] reported, capsular invasion is more frequent and severe in pleomorphic adenomas larger than $40 \mathrm{~mm}$ generally containing more myxoid stroma which promotes vascular invasion. The advantages of ED include the removal of the mass with adequate margins of healthy parotid tissue and a reduction in the side effects after surgery, thus preserving the parotid salivary function. A prolonged followup is recommended $[20,21]$.

\section{Conflict of Interests}

The authors declare that they have no competing interests.

\section{Authors' Contribution}

Maria Giulia Cristofaro conceived the study and participated in the acquisition data. Eugenia Allegra reviewed the literature and helped to draft the paper. Amerigo Giudice participated to the acquisition and interpretation data. Walter Colangeli, Davide Caruso, and Ida Barca carried out the acquisition of data. Mario Giudice carried out the supervision of the study and revised the final version of the paper.

\section{References}

[1] N. Papadogeorgakis, "Partial superficial parotidectomy as the method of choice for treating pleomorphic adenomas of the parotid gland," The British Journal of Oral and Maxillofacial Surgery, vol. 49, no. 6, pp. 447-450, 2011.

[2] L. Colgan, C. P. Chambers, W. J. R. Currie, and W. S. Hislop, "An overview of parotid gland surgery by a single OMFS surgeon in a district general hospital," British Journal of Oral and Maxillofacial Surgery, vol. 49, p. s45, 2011.

[3] K. S. George and M. McGurk, "Extracapsular dissection: minimal resection for benign parotid tumours," British Journal of Oral and Maxillofacial Surgery, vol. 49, no. 6, pp. 451-454, 2011. 
[4] M. G. Cristofaro, E. Allegra, and M. Giudice, “Two new localizations of solitary fibrous tumor in the italian population: parotid gland and oral cavity-review of the literature," Journal of Oral and Maxillofacial Surgery, vol. 70, no. 10, pp. 2360-2367, 2012.

[5] J. E. Woods, G. C. Chong, and O. H. Beahrs, "Experience with 1,360 primary parotid tumors," The American Journal of Surgery, vol. 130, no. 4, pp. 460-462, 1975.

[6] J. D. Maynard, "Management of pleomorphic adenoma of the parotid," British Journal of Surgery, vol. 75, no. 4, pp. 305-308, 1988.

[7] R. L. Witt and L. Rejto, "Pleomorphic adenoma: extracapsular dissection versus partial superficial parotidectomy with facial nerve dissection," Delaware Medical Journal, vol. 81, no. 3, pp. 119-125, 2009.

[8] A. J. N. Prichard, R. P. E. Barton, and A. A. Narula, "Complications of superficial parotidectomy versus extracapsular lumpectomy in the treatment of benign parotid lesions," Journal of the Royal College of Surgeons of Edinburgh, vol. 37, no. 3, pp. 155-158, 1992.

[9] T. Yamashita, K. Tomoda, and T. Kumazawa, "The usefulness of partial parotidectomy for benign parotid gland tumors. A retrospective study of 306 cases," Acta Oto-Laryngologica, vol. 500, pp. 113-116, 1993.

[10] N. Klintworth, J. Zenk, M. Koch, and H. Iro, "Postoperative complications after extracapsular dissection of benign parotid lesions with particular reference to facial nerve function," Laryngoscope, vol. 120, no. 3, pp. 484-490, 2010.

[11] G. D. Orabona, P. Bonavolontà, G. Iaconetta, R. Forte, and L. Califano, "Surgical management of benign tumors of the parotid gland: extracapsular dissection versus superficial parotidectomy-our experience in 232 cases," Journal of Oral and Maxillofacial Surgery, vol. 71, no. 2, pp. 410-413, 2013.

[12] J. Piekarski, D. Nejc, W. Szymczak, K. Wroǹski, and A. Jeziorski, "Results of extracapsular dissection of pleomorphic adenoma of parotid gland," Journal of Oral and Maxillofacial Surgery, vol. 62, no. 10, pp. 1198-1202, 2004.

[13] M. Mcgurk, A. Renehan, E. N. Gleave, and B. D. Hancock, "Clinical significance of the tumour capsule in the treatment of parotid pleomorphic adenomas," British Journal of Surgery, vol. 83, no. 12, pp. 1747-1749, 1996.

[14] R. L. Witt, "The significance of the margin in parotid surgery for pleomorphic adenoma," Laryngoscope, vol. 112, no. 12, pp. 2141-2154, 2002.

[15] J. L. Roh, H. S. Kim, and C. I. Park, "Randomized clinical trial comparing partial parotidectomy versus superficial or total parotidectomy," British Journal of Surgery, vol. 94, no. 9, pp. 1081-1087, 2007.

[16] K. George and M. McGurk, "Extra-capsular dissection of benign parotid tumours-a 10-year experience," British Journal of Oral and Maxillofacial Surgery, vol. 48, supplement 1, p. S8, 2010.

[17] P. Zbären, V. V. Poorten, R. L. Witt et al., "Pleomorphic adenoma of the parotid: formal parotidectomy or limited surgery?" American Journal of Surgery, vol. 205, no. 1, pp. 109-118, 2013.

[18] G. D. Orabona, P. Bonavolontà, G. Iaconetta, R. Forte, and L. Califano, "Surgical management of benign tumors of the parotid gland: Extracapsular dissection versus superficial parotidectomy-our experience in 232 cases," Journal of Oral and Maxillofacial Surgery, vol. 71, no. 2, pp. 410-413, 2013.

[19] S. Maruyama, J. Cheng, M. Yamazaki, A. Liu, and T. Saku, "Keratinocyte growth factor colocalized with perlecan at the site of capsular invasion and vascular involvement in salivary pleomorphic adenomas," Journal of Oral Pathology and Medicine, vol. 38, no. 4, pp. 377-385, 2009.

[20] L. Barzan and M. Pin, "Extra-capsular dissection in benign parotid tumors," Oral Oncology, vol. 48, no. 10, pp. 977-979, 2012.

[21] M. Fukushima, M. Miyaguchi, and T. Kitahara, "Extracapsular dissection: minimally invasive surgery applied to patients with parotid pleomorphic adenoma," Acta Oto-Laryngologica, vol. 131, no. 6, pp. 653-659, 2011. 


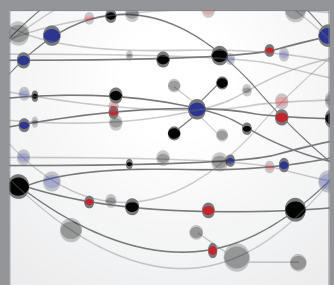

The Scientific World Journal
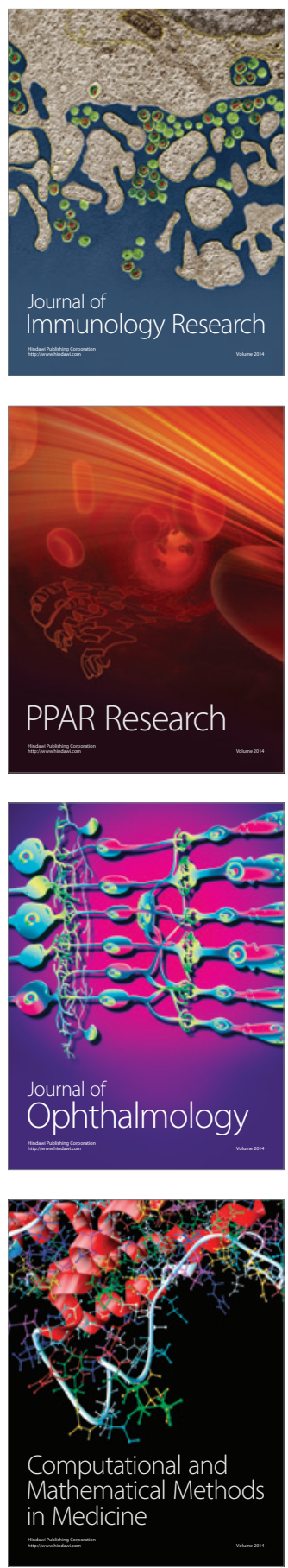

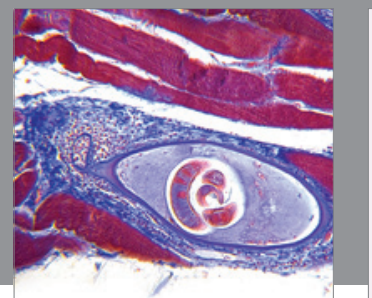

Gastroenterology

Research and Practice
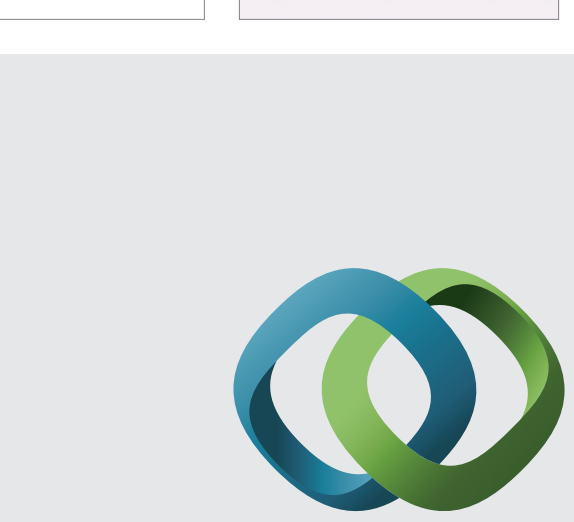

\section{Hindawi}

Submit your manuscripts at

http://www.hindawi.com
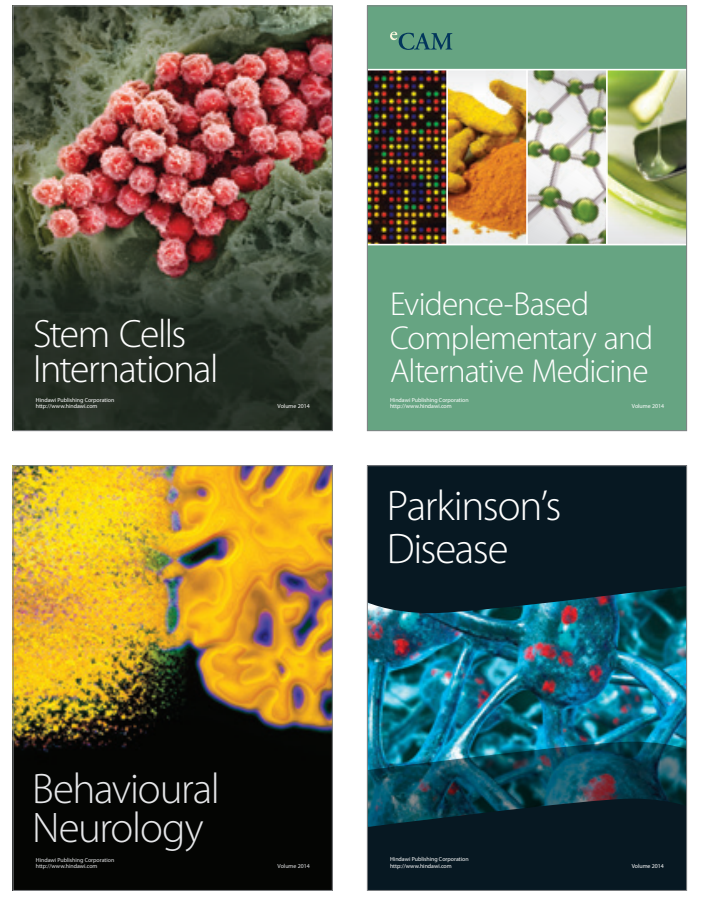
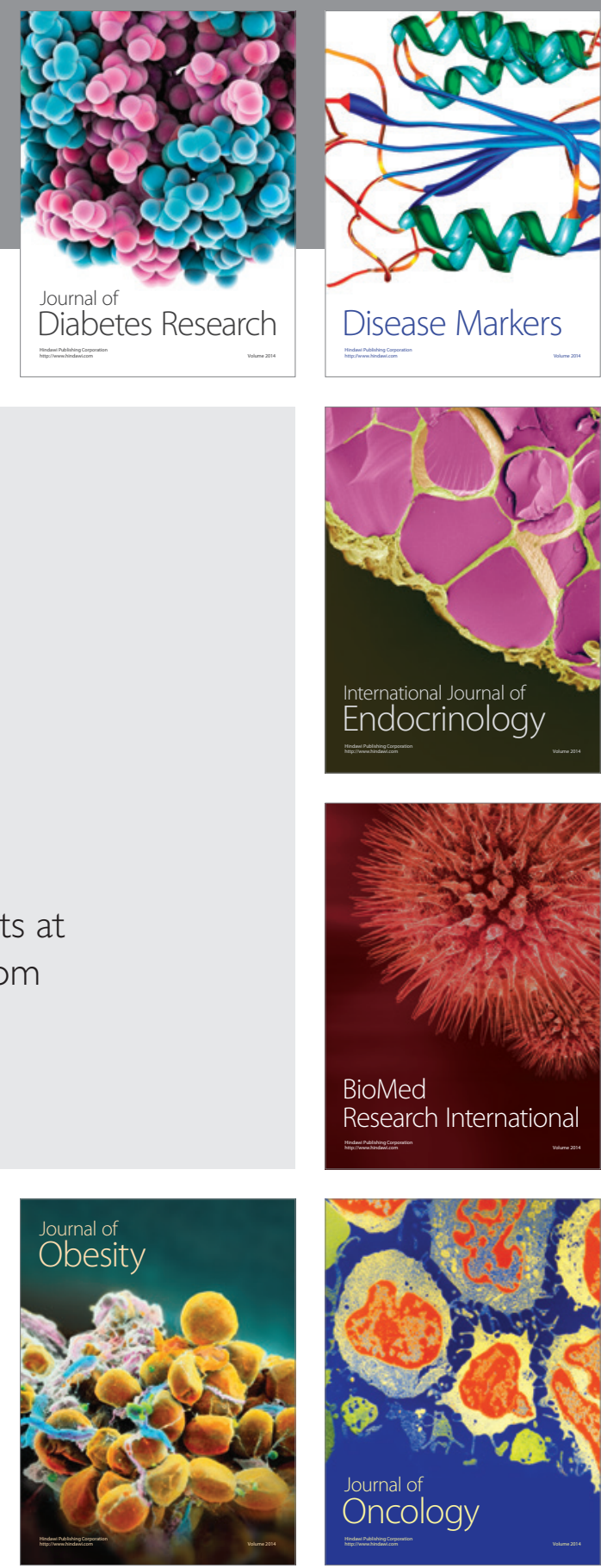

Disease Markers
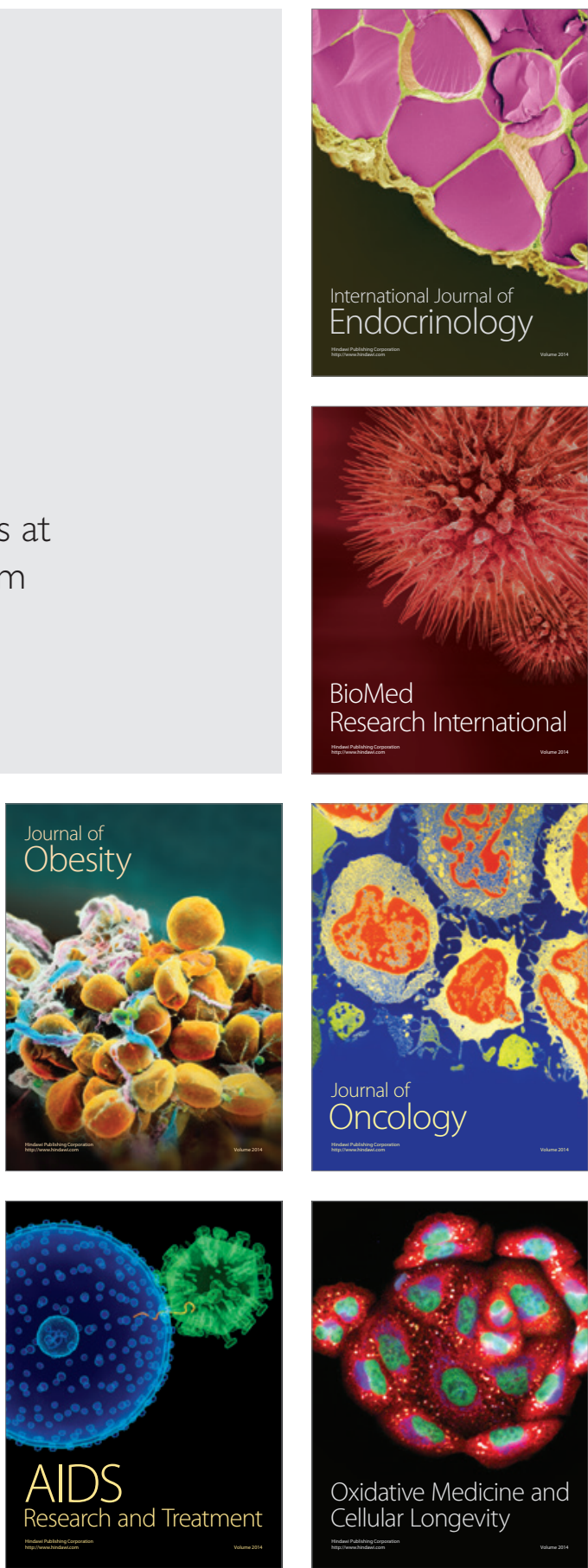